\title{
Electrochromism and Swelling of Polypyrrole Membranes: An Electrochemical and Ellipsometric Study
}

\author{
J. O. Zerbino, ${ }^{1}$ M. G. Sustersic, ${ }^{2}$ C. Falivene, ${ }^{2}$ N. Avaca, ${ }^{2}$ and A. Maltz ${ }^{3}$ \\ ${ }^{1}$ Instituto de Fisicoquímica, INIFTA, CIC, Suc. 4, C.C. 16, 1900 La Plata, Argentina \\ ${ }^{2}$ Facultad de Ingeniería, FICES, UNSL, 25 de Mayo 384 C.P. 5730. Villa Mercedes, San Luis, Argentina \\ ${ }^{3}$ Departamento de Matemática, Facultad de Ciencias Exactas, UNLP, Calle 115 y 50, 1900 La Plata, Argentina
}

Correspondence should be addressed to J. O. Zerbino, jzerbino@inifta.unlp.edu.ar

Received 18 March 2011; Accepted 16 May 2011

Academic Editor: Bengi Uslu

Copyright () 2011 J. O. Zerbino et al. This is an open access article distributed under the Creative Commons Attribution License, which permits unrestricted use, distribution, and reproduction in any medium, provided the original work is properly cited.

\begin{abstract}
The growth of polypyrrole (Ppy) layers on gold electrodes in nearly neutral pH solutions is analysed using "in situ" voltametric and ellipsometric techniques. Different film structures are obtained depending on the potentiodynamic programme and the composition of the electrolyte. More compact dodecylsulphate-(DS) doped Ppy layers were grown at $1.2 \mathrm{~V}$ versus RHE than those obtained by applying a higher potential. The more compact layers correspond to the growth of an oxidised Ppy/DS layer that shows low pseudo capacity behaviour. After dipping, the doped Ppy/DS film in $\mathrm{KCl}$ solution-significant variations in optical indices and thickness are detected as a function of the applied potential. Higher electrochromism as well as decrease in film thickness after cathodisation is achieved. The optical indices and the thickness of the Ppy layer formed under different applied potential/time programmes are estimated.
\end{abstract}

\section{Introduction}

Conducting polymers and particularly polypyrrole, Ppy, is extensively used in sensors, oxygen sensing, microelectronic mechanical systems MEMS, metal-insulator-semiconductor field effect transistors, drug release, actuators, water treatment, protective coatings against corrosion, and analytical displays [1-13].

Polypyrrole (Ppy) shows high permeability and selectivity for the detection of catecholamines in different electrolytes owing to anionic species exclusion by the interaction with negative charges into the film [14-18].

The kinetics of growth and the final structure of the Ppy layers depend on the potential programme, the anodic limit, and on the cycling time [19-22]. On the other hand, the presence of different ions in the electrolyte modifies the layer growth rate, the voltametric response, and the interfacial capacity. These effects are related to variations in pyrrole absorption, concentration of radicals, structure of the oligomers initially formed during anodisation, and partial water exchange taking place together with ion's uptake processes into the membrane [23-25].
Oxidation of Ppy yields positive fixed charges on the polymer networks. Commonly prepared Ppy layers exhibit anion exchange during the oxidation cycle. The Ppy matrix in the reduced state is electroneutral and a poor ionic and electronic conductor.

The properties of these membranes can be modified by doping the Ppy with large and bulky shaped anions such as dodecylsulphate, dodecylsulphonate, paratoluensulphonate, and so forth. This has been achieved by electrooxidation in solutions containing the large anions, which are thereby incorporated into the film as fixed charges. In electroanalysis, these membranes offer good selectivity and high stability during prolonged switching conditions.

Cation exchange takes place on these PPy modified layers due to the high immobility of these ions through the PPy chain $[26,27]$.

$$
\begin{gathered}
\mathrm{Ppy}+\mathrm{X}^{(\mathrm{S})}-\mathrm{e} \longleftrightarrow \mathrm{Ppy}^{(+)} \mathrm{X}, \\
\mathrm{Ppy} / \mathrm{ROSO}_{3} \mathrm{Na}^{+}-\mathrm{e} \longleftrightarrow \mathrm{Ppy}^{(+)} / \mathrm{ROSO}_{3}+\mathrm{Na}^{+(\mathrm{S})},
\end{gathered}
$$

the superscript " $\mathrm{S}$ " indicates that the species is in the electrolyte. 


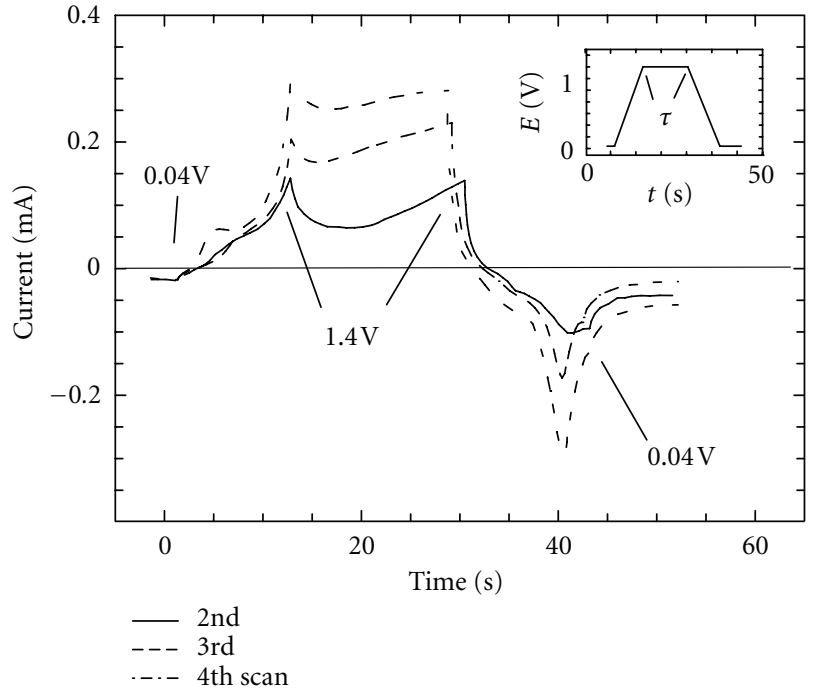

(a)

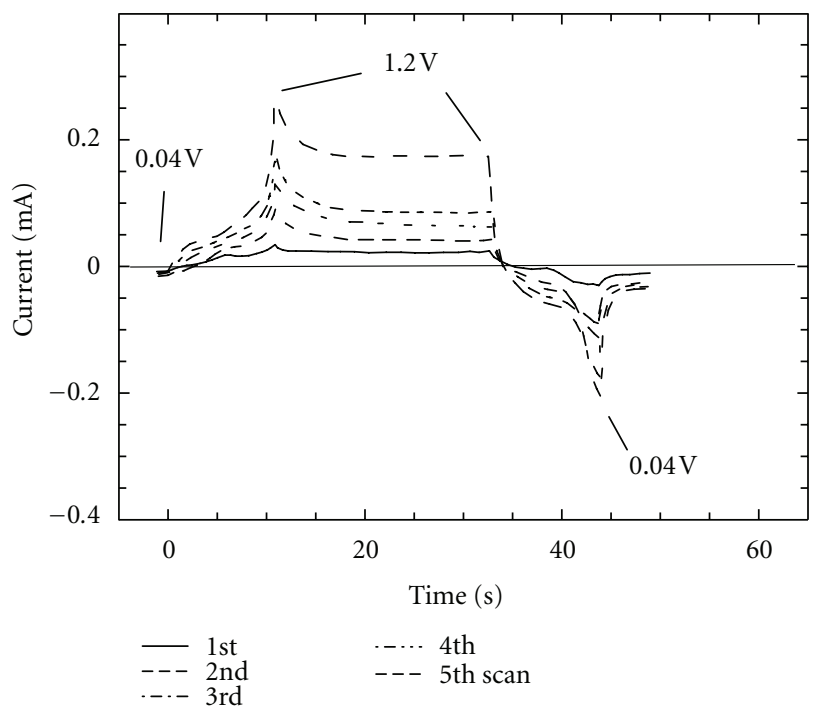

(b)

FIgURE 1: Potential/time programmes used in polypyrrole layer growth. Potential sweep in $0.1 \mathrm{M}$ SDS, $0.1 \mathrm{M}$ Py solution from $E c=0.04 \mathrm{~V}$ to $E a$ followed by a holding time $\tau$ at $E a$ and consecutive cathodic scan to $E c$. Scan rate $100 \mathrm{mV} / \mathrm{s}$. The different curves show the evolution of current/potential/time profiles for successive cycling using either (a) $E a=1.4 \mathrm{~V}$ with $\tau=15 \mathrm{~s}$ or (b) $E a=1.2 \mathrm{~V}$ with $\tau=20 \mathrm{~s}$.

Ellipsometry can be applied "in situ" to characterise the layer structure seeing that the optical signal is very sensitive to the modifications produced by the polarisation of the electrode. Recent work has investigated the characteristics of electrodeposited Ppy on gold in buffer phosphate solution [15].

In this work, cyclic voltammetry and ellipsometry were used to investigate the effect of the potential on the growth of doped Ppy/DS layers.

\section{Experimental}

Experimental conditions were similar to those described in previous work $[28,29]$. The gold electrode was made by axially fitting a polycrystalline gold plaque (99.99\% purity, $1.5 \mathrm{~mm}$ thick) into a Teflon sheath. It was polished to a mirror finish with 1.0, 0.3 and $0.05 \mu \mathrm{m}$ alumina powders. The electrode, horizontally placed in the cell, had a total area of $0.55 \mathrm{~cm}^{2}$ and an area sampled by ellipsometry of about $2 \mathrm{~mm}^{2}$. All experiments were performed under nitrogen bubbling. The potentials were referred to the reversible hydrogen electrode (RHE) in the same solution.

The freshly polished metal was pretreated by scanning five cycles in the potential region $0.1 \mathrm{~V}<E<1.70 \mathrm{~V}$.

For the ellipsometric measurements, the light wavelength was selected by interposing adequate filters in the range $405<$ $\lambda<580 \mathrm{~nm}$. The on manual ellipsometer, Rudolph Research Fairfield, NJ, USA, type 43702-200E, Serial No 4210, takes about $1 \mathrm{~min}$ to measure the $\Delta / \Psi$ parameters. The electrode was illuminated through optically polished glass lateral windows $20 \mathrm{~mm}$ in diameter using an incident angle of $69^{\circ}$. The optical indices of the substrate were obtained at open circuit in the aqueous electrolyte, from the ellipsometric parameters of the polished gold electrode. The resulting values were in good agreement with previously reported data $[15,28,29]$.

The Ppy films were anodically grown in the cell containing 0.1 M Pyrrole, Py, Sigma Aldrich (SAFC: W338605), $0.1 \mathrm{M}$ sodium dodecylsulphate, SDS, Riedel-de Haën, and aqueous solution. After polymerisation, the electrolyte of the cell was replaced by a new SDS solution free of pyrrole.

The changes in the ellipsometric parameters $\Delta$ and $\Psi$ after successive deposition cycles of Ppy were measured using the following potential/time programme: the potential was scanned at $100 \mathrm{mV} / \mathrm{s}$ between the cathodic potential limit $E c$ $=0.1 \mathrm{~V}$ and the anodic limit $E a$ followed by a holding time, $\tau$, at $E a$. Next, a cathodic scan at $100 \mathrm{mV} / \mathrm{s}$ was applied between $E a$ and $E c$, and then successively measured values of $\Delta$ and $\Psi$ were taken at $E c$ with intervals of 2 min.

\section{Calculations}

The simplest model assumes a single homogeneous film. The real part of the refraction index of the film, $n$, the imaginary part of the refraction index or absorption coefficient, $k$, and the thickness, $d$, are calculated using the gradient technique $[28,29]$.

In the case of inhomogeneous layers, the high number of parameters makes the determination of the structure very cumbersome. However, the single homogeneous film model is a good first approximation in the description of the interface, and these indices correspond to effective optical indices for the composite fibre/occluded electrolyte layer $[28,29]$. In the case of composite materials, the effective medium theory using either Maxwell Garnett or Bruggeman formalisms relates the optical constant of the polymeric fibre phase and that of the electrolyte with the volume fraction of 

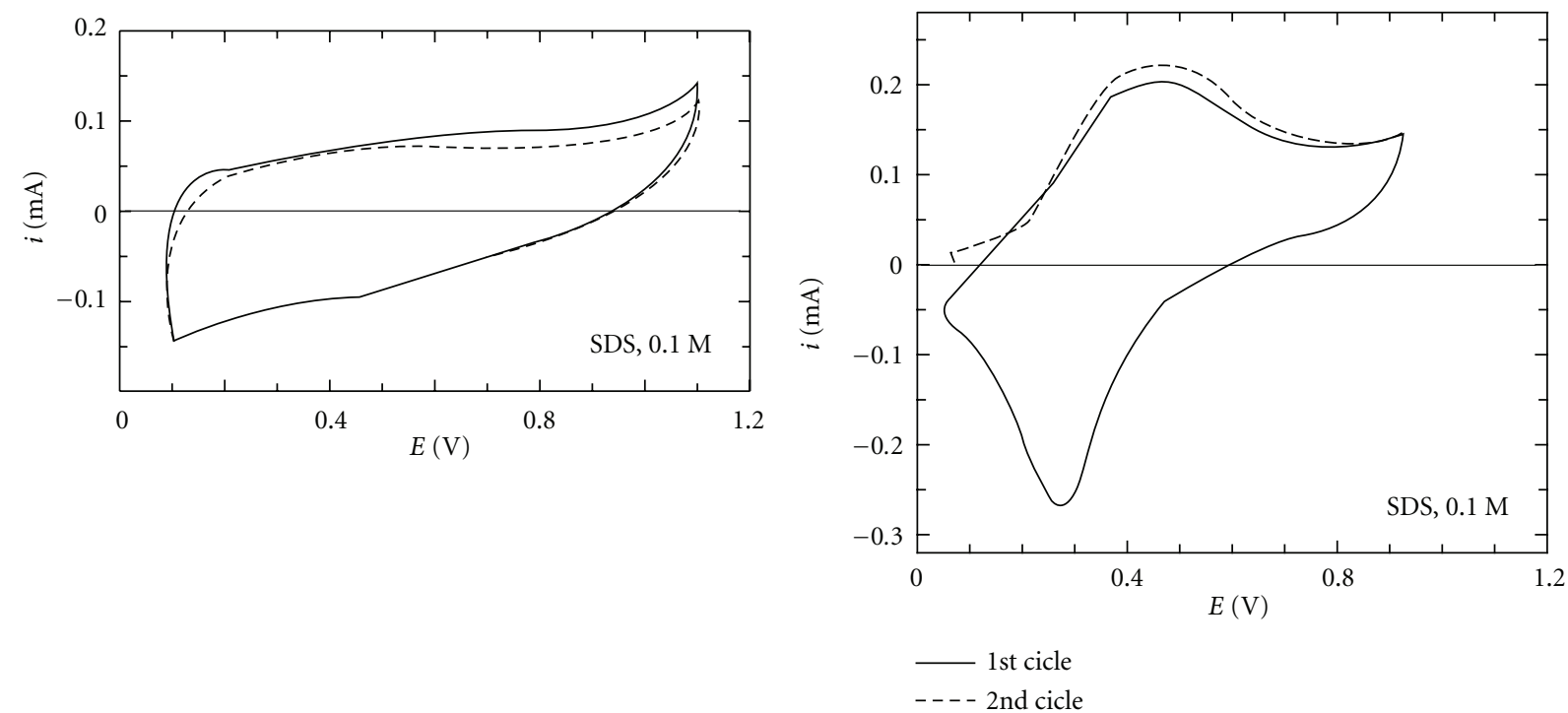

(a)

(b)

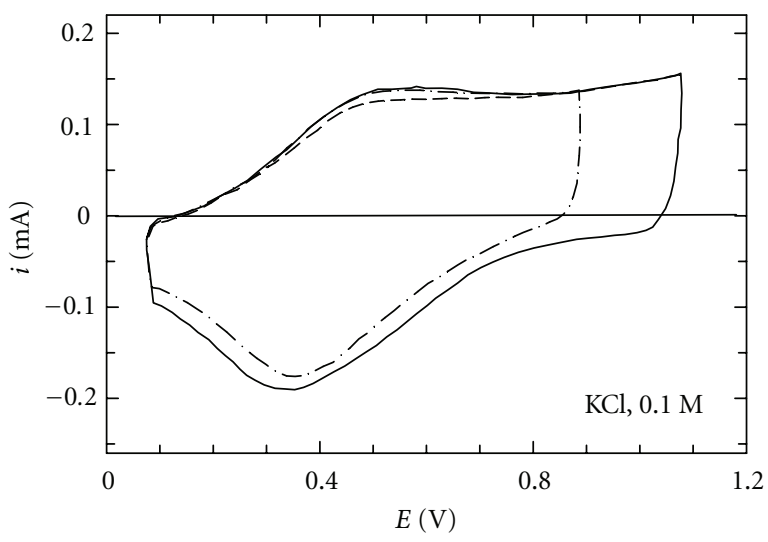

(c)

FIgURE 2: Current/potential voltammograms obtained scanning at $100 \mathrm{mV} / \mathrm{s}$ between $E c=0.04 \mathrm{~V}$ and either $E a=0.9 \mathrm{~V}$ or $E a=1.1 \mathrm{~V}$. Pseudocapacitive response observed after five anodic cycles using (a) $E a=1.2 \mathrm{~V}$ with $\tau=20 \mathrm{~s}$, and (b) $E a=1.4 \mathrm{~V}$ with $\tau=15 \mathrm{~s}$. (a) and (b) in SDS solution free of Py, (c) the same electrode shown in Figure 2(a) and after immersion in $0.1 \mathrm{M} \mathrm{KCl.}$

the components providing the effective optical constants for the composite polymer/electrolyte.

The fitting procedure minimises the function $G$ :

$$
G=\sum\left(\Delta^{\mathrm{ex}}{ }_{i j}-\Delta^{\text {the }}{ }_{i j}\right)^{2}+\left(\Psi^{\mathrm{ex}}{ }_{i j}-\Psi^{\text {the }}{ }_{i j}\right)^{2},
$$

where the subindex $i$ corresponds to the optical data measured at different $\lambda_{j}$, and the sub index $j$ corresponds to different cycling deposits or thicknesses $d_{i}$.

In the simplest process, the layer grows in thickness with constant compactness and composition bearing stable $n$ and $k$ values. In many cases, the fitting of the $n, k$, and $d$ values for a sequential set of thicknesses allows to evaluate variations in the compactness of the film as a function of the distance to the electrode. In this procedure, it is very important to use accurate initial values in the fitting, which can usually be found fitting the complete set of thicknesses. Another possibility is to increase the amount of optical data for a given layer measuring the $\Delta$ and $\Psi$ data at different $\lambda_{j}$. This allows increasing the amount of experimental data to find univocal values of thicknesses and optical constants.

The optimisation method converges after $m$ iterations, to theoretical $\Delta^{\text {the }} i j, \Psi^{\text {the }}{ }_{i j}$ values. The convergence is fulfilled after $m$ iterations when (a) the Euclidean norm of the arrangement $p_{m}-p_{m+1}$ tends to 0 , (b) $G\left(p_{m}\right)>G\left(p_{m+1}\right)>$ $G\left(p_{m+2}\right)$, and (c) $\partial G_{m} / \partial p$ tends to 0 .

\section{Results and Discussion}

Several electrochemical perturbations are customarily employed for the deposition process of Ppy layers. Potentiodynamic polymerisation (cyclic voltammetry) probably favours the formation of disordered chains [30] just because the continuous change between its neutral (insulating) and its doped (conducting) state usually involves compaction and opening of the polymeric network. On the other hand, galvanostatic pulses applied during relatively long periods of polarisation produce thick and porous deposits due to the 


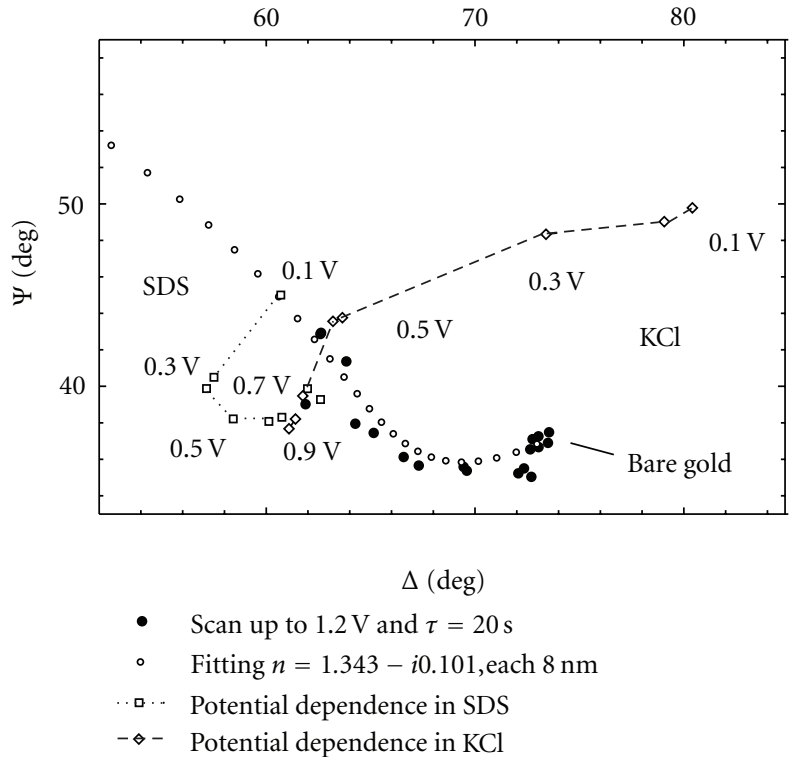

(a)

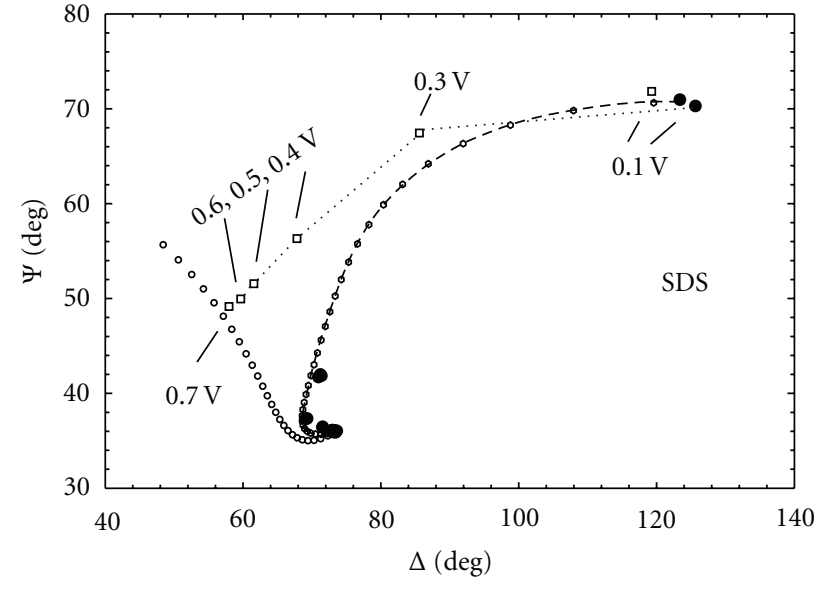

- $\quad$ Scan up to $1.4 \mathrm{~V}$ and $\tau=35 \mathrm{~s}$

.. a. Potential dependence in SDS

- $n=1.376-i 0.0723$, each $8 \mathrm{~nm}$

- $n=1.343-i 0.101$, each $8 \mathrm{~nm}$

(b)

Figure 3: $(\bullet)$ Evolution of the experimental parameters $\Delta$ and $\Psi$ after successive cycles in the condition of Figure 1, namely, (a) Ea=1.2 V and $\tau=20 \mathrm{~s}$, (b) $E a=1.4 \mathrm{~V}$ and $\tau=15 \mathrm{~s}$. The figures correspond to number of cycles. Evolution of the thicker film changing the potentials in both $(\square)$ : SDS and $(\diamond)$ : after immersion in $\mathrm{KCl} .(\bigcirc)$ : Theoretical values corresponding to a layer of optical index $n$ and increasing the thickness, $d$, every $8 \mathrm{~nm}$. The film obtained at $E a=1.2 \mathrm{~V}$ fits $n=1.343-i 0.101$ and that obtained at $E a=1.4 \mathrm{~V}$ fits $n=1.3476-i 0.0723$. Owing of the change in the $\Delta / \Psi$ plot scale, both fitted curves are plotted in (b) for comparison.

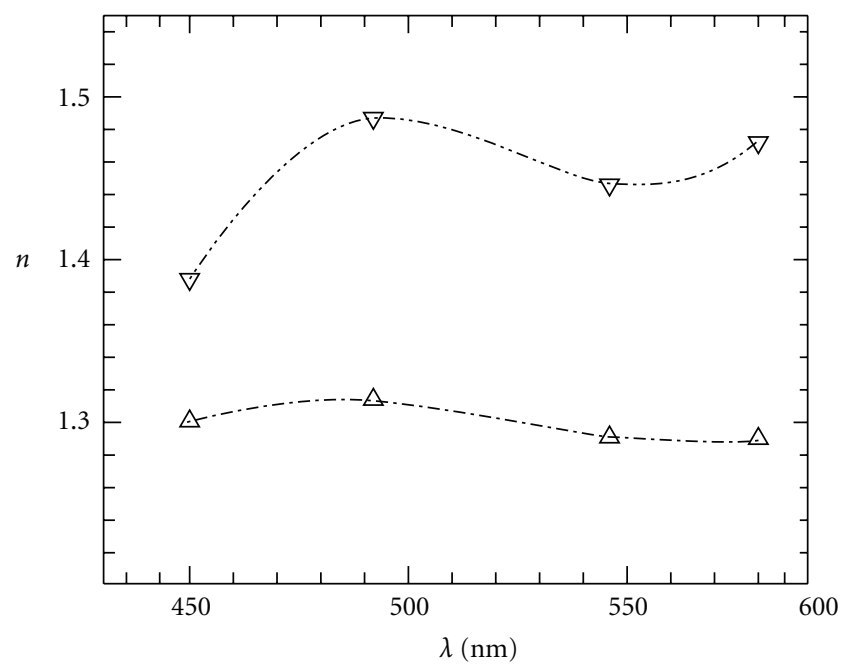

(a)

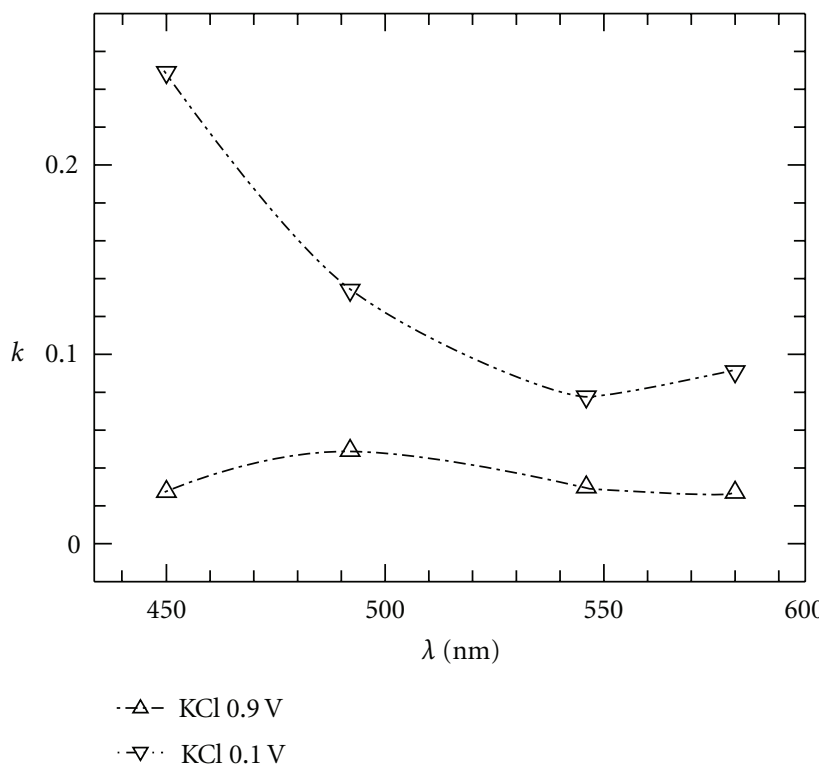

(b)

FIGURE 4: Calculated refractive index $n$ and absorption index $k$ for illuminating light beam in the region $450<\lambda<580$, for the film obtained after five cycles with $E a=1.2 \mathrm{~V}$ and $\tau=20 \mathrm{~s}$ after immersion in $\mathrm{KCl}$.

deflection of the monomer concentration near the vicinity of the electrode.

Figure 1 shows the current potential profile obtained after applying successive anodic cycles at $1.2 \mathrm{~V}$ and $1.4 \mathrm{~V}$ in $0.1 \mathrm{M}$ Pyrrole, $0.1 \mathrm{M}$ SDS solution. For $E a=1.2 \mathrm{~V}$, a continuous decrease on the current during the anodising time $\tau$ is observed. Moreover, the anodic scans show a peak at $0.45 \mathrm{~V}$ that increases with the successive cycles. This evidences the electrooxidation of the Ppy deposited in the previous cycles, and the increasing cathodic peak currents highlights its reduction. Figure 1(b) shows similar current/time profiles. However, a current increase occurs at $E a=1.4 \mathrm{~V}$ after about 


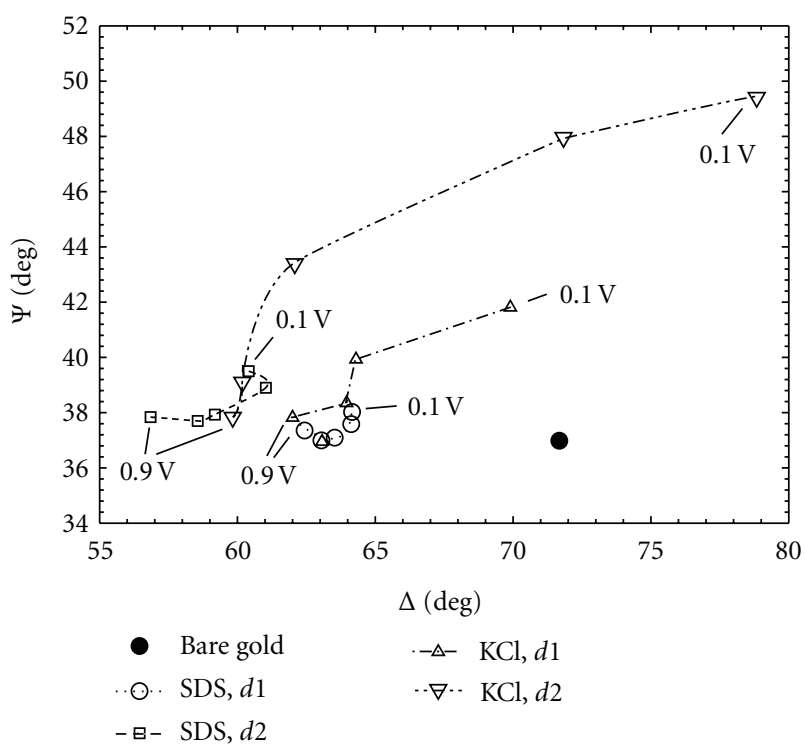

Figure 5: Evolution of the experimental parameters $\Delta$ and $\Psi$ as a function of the applied potential for Ppy film grown in SDS, after applying both four or five successive cycles and using $E a=1.2 \mathrm{~V}, \tau$ $=20 \mathrm{~s}$. $(\bigcirc)$ in SDS and $(\square)$ after immersion in $\mathrm{KCl}$.

$\tau=5 \mathrm{~s}$. This effect probably stems from the anodic oxidation of the Py dissolved in the SDS micelles, which can solvate part of the reaction intermediates (free radicals) as well as the resulting Ppy oligomers. DS has a charged, polar end and a hydrophobic end. The charged end facing out into the solution can be maintained during polymerisation, even though the negative group is being incorporated into the polymer as a counter ion. Alternatively, the polymer, which is deposited subsequently, could also develop polar surface properties [31].

Figures 2(a) and 2(b) shows voltametric scans at $100 \mathrm{mV} / \mathrm{s}$ obtained from Ppy electrodeposited either at 1.2 or at $1.4 \mathrm{~V}$. The plot of Figure 2 (a) shows a small anodic peak at $0.68 \mathrm{~V}$ and another cathodic one at $0.48 \mathrm{~V}$. On the other side, Figure 2(b) shows very well-defined peaks at $0.45 \mathrm{~V}$ and $0.38 \mathrm{~V}$. The cathodic charge that involves in the cathodic scan is $\mathrm{Q}_{2 a}=0.58 \mathrm{mC}$ and $\mathrm{Q}_{2 b}=0.70 \mathrm{mC}$. Nevertheless, the current jump at potentials near the sweep inversion shows that the double layer capacity for the film grown at $1.2 \mathrm{~V}$ is higher than that grown at $1.4 \mathrm{~V}$, Figures $2(\mathrm{a})$ and 2(b). After immersion in $0.1 \mathrm{M} \mathrm{KCl}$ solution, the film grown in the experiment of Figure 2(a) has a remarkably high pseudocapacitive charge $\left(\mathrm{Q}_{2 c}=0.73 \mathrm{mC}\right)$.

Voltammograms with a relatively high double layer capacity have being previously reported in the case of Ppy films doped with PSS [32]. Three forms of Ppy has been reported, $\mathrm{Ppy}(\mathrm{I})$ the regular polymer, contains longer chains, (with length up to 64 units), Ppy(II) containing short oligo pyrrole units (with length between 12 and 16 units), while a cross-linked material referred to as Py-III is generated at high potentials. The oxidation peak at more negative potentials may indicate the presence of Ppy(II) [30, 33]. However, other factors may influence the polymerisation processes and the redox capacity, such as different solvents, additives, and electrolytes. The concentration of SDS trapped in the network may regulate the redox properties of the layer. In the case of Ppy/SDS films subjected to a very thin polystyrene coverage, used to increase the hydrophobicity of the polymer/electrolyte interface, the voltammogram shows a cathodic shift of about $0.5 \mathrm{~V}$ of the redox couple, related to the Ppy layer free of SDS, for the electrode switching in $0.1 \mathrm{M} \mathrm{KCl}[34]$.

Figure 3 shows the evolution of the ellipsometric parameters $\Delta / \Psi$ during the layer growth. After each potential cycle, three successive measures at $0.1 \mathrm{~V}$ are taken with intervals of $2 \mathrm{~min}$. Figure $3(\mathrm{a})$ shows for both the $3 \mathrm{rd}$ and the 4 th cycle a small increase in the $\Delta$ values during the holding time at $0.1 \mathrm{~V}$. After $2 \mathrm{~min}$ at $0.1 \mathrm{~V}$, the data of the third measure practically reproduces the second one. In the case of the 5th cycle, the opposite tendency occurs and the $\Delta / \Psi$ values show some instability. According to the calculation procedure mentioned above, the whole set of experimental $\Delta / \Psi$ values corresponding to the five cycles were fitted for common $n$ and $k$ parameters and different $d$. For the obtained fitted $n$ and $k$ values, the theoretical $\Delta / \Psi$ curve was plotted. A maximum thickness $d$ of about $122 \mathrm{~nm}$, and $n=$ $1.343-i 0.101$ was obtained. Using the same procedure, the fitting corresponding to the deposit obtained at $1.4 \mathrm{~V}$ values of $n=1.376-i 0.0723$ and a maximum $d=254 \mathrm{~nm}$ was obtained.

Likewise, Figure 3(b) shows the potential dependence of the experimental $\Delta / \Psi$ values in $0.1 \mathrm{M}$ SDS solution, free of pyrrole, corresponding to the film grown at $1.4 \mathrm{~V}$.

In the experiment of the Figure 3(a), the $\Delta / \Psi$ measurements in SDS shows low dependence with the potential and some instability during the holding time and the successive cycles. Otherwise, a very large and reproducible change in $\Delta / \Psi$ occurs, after dipping in $\mathrm{KCl}$.

On the other side, Figure 3(b) shows that, for the film grown at $1.4 \mathrm{~V}$ after oxidation at $0.7 \mathrm{~V}$, the $\Delta / \Psi$ values fit the theoretical curve $n=1.343-i 0.101$. Then, a thickness of $164 \mathrm{~nm}$ is obtained. This theoretical curve is shown in Figure 3(a), and it is transferred to the plot scale of Figure 3(b) for comparison.

Figure 4 shows the calculated optical indices at 0.1 and $0.9 \mathrm{~V}$ for the film grown at $1.2 \mathrm{~V}$ and dipped in $\mathrm{KCl}$ solution. In this fitting, the optical data taken at 450, 492, 546, and $580 \mathrm{~nm}$ are fitted independently at both potentials and thickness $d_{\text {ox }}$ and $d_{\text {red }}$ corresponding to the oxidised and the reduced state are obtained. This way, values of $d_{\mathrm{ox}}=$ 165 and $d_{\text {red }}=120 \mathrm{~nm}$, which show a swelling of the film after reduction, are obtained. The $k$ increase observed for $\lambda=400 \mathrm{~nm}$ agrees with reported spectroelectrochemical measurements [22]. The optical indices of the film in SDS solution corresponding to the anodic and the cathodic potential limit are very similar to that corresponding to the oxidised state in $\mathrm{KCl}$ [35].

Moreover, the Ppy/SDS electrode recently dipped in $\mathrm{KCl}$ solution adjusts spontaneously to an open circuit potential of about $0.88 \mathrm{~V}$. These results show that even polarised at $0.1 \mathrm{~V}$ the Ppy/SDS layer grown at $1.2 \mathrm{~V}$ remains highly oxidized, and the cycling in Figure 2(a) corresponds to a switching between highly oxidized states with a scarce Ppy network 


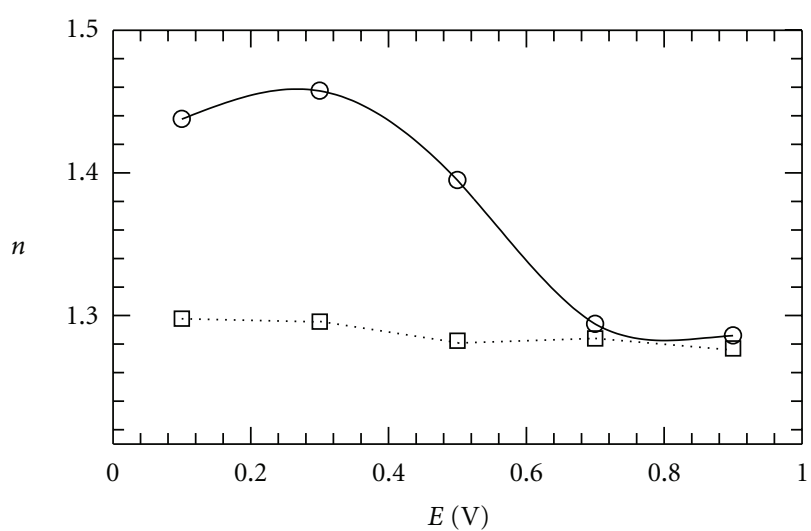

(a)

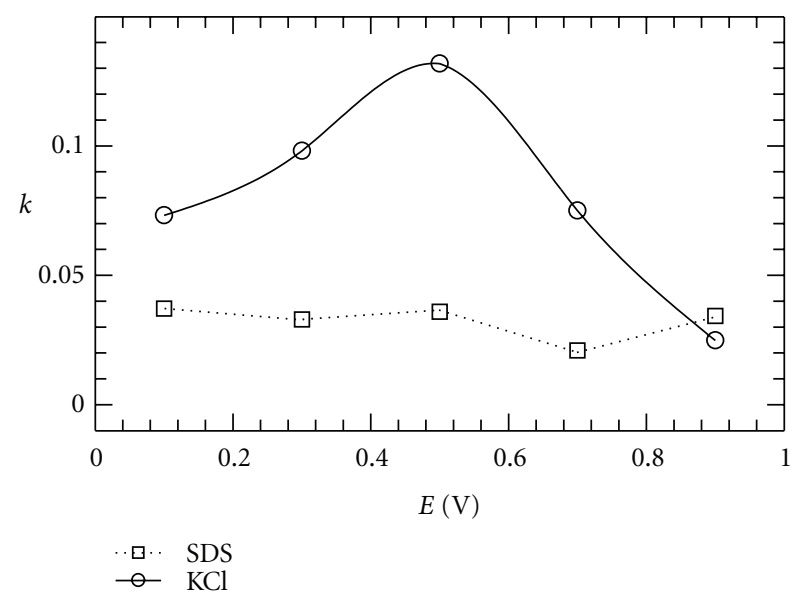

(b)

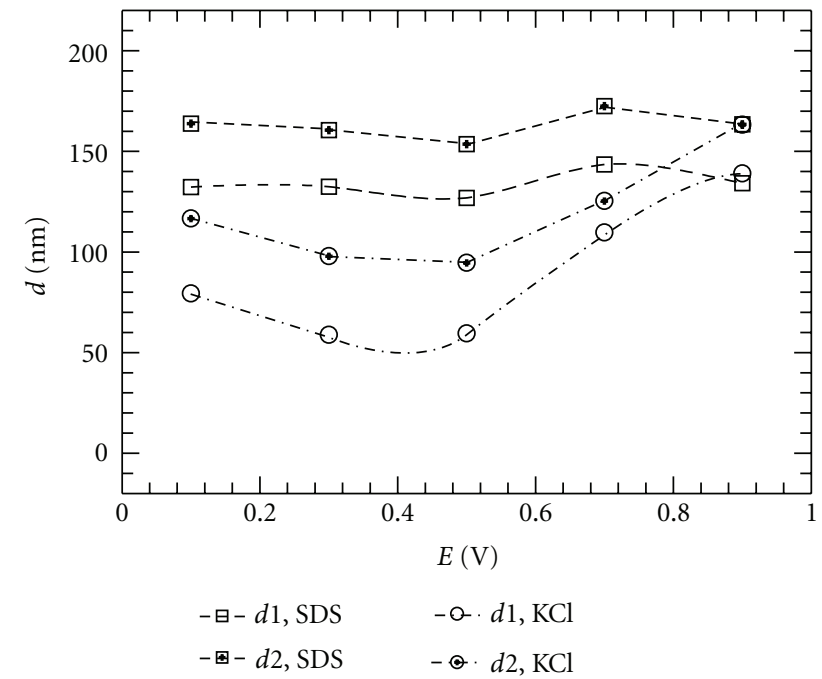

(c)

Figure 6: Calculated thickness, $d$, and optical indices, $n, k$, for the Ppy layers already described in Figure 5 and for an illuminating light beam of $\lambda=546 \mathrm{~nm}$. ( $\bigcirc)$ in SDS and $(\square)$ after immersion in $\mathrm{KCl}$.

reduction. The higher values of $n$ at $0.1 \mathrm{~V}$ correspond to the shrinking of the layer with exchange of cations and expulsion of solvent.

The $\Delta / \Psi$ values that correspond to two Ppy/SDS-independent experiments obtained at $1.2 \mathrm{~V}$ applying four and five cycles are plotted in Figure 5. The optical data in the SDS solution free of pyrrole show a potential evolution, in the region of $0.1<E<0.9 \mathrm{~V}$ stepping every $0.2 \mathrm{~V}$. They display a small clockwise arch. After changing the electrolyte with new $\mathrm{KCl}$ solution, the switching shows a counterclockwise and higher potential dependence. Assuming common optical indices at each fixed potential for both deposited films, univocal values of $n, k$, and $d$ are obtained. The $n, k$, and $d$ fitted values are plotted as a function of the potential in Figure 6. In the case of SDS solution, very small $n, k$, and $d$ dependencies on $E$ are noticed. However, a shrinking in the thickness results during the progressive cathodisation in $\mathrm{KCl}$ solution, which is the maximum for about $0.4 \mathrm{~V}$. The $k$ versus $E$ plot shows a maximum value in $k$ for about $0.5 \mathrm{~V}$.
The shrinking of the membrane may partially increase the values of the optical constants. For a pure substance, $n$ and $k$ are independent of the thickness but Maxwell Garnett and Bruggeman predict an increase of the effective $n$ and $k$ indices for a composite due to the extraction of water [36]. However, the increase in $\mathrm{k}$ is so significant that it shows a structural change in the Ppy phase.

The chain structure, compactness of both the bulk and the surface of the composite Ppy/electrolyte, as well as the concentration and mobility of counter anions become critical factors in the behaviour of the membrane. Bipolarons are equivalent to di ionic states of a system generated after oxidation of the neutral state initiated through the polaron state monocation. In the oxidation process, the structural relaxation causes a local distortion of the chain in the vicinity of the charge, and the twisted benzoid-like network turns into a quinoid-like structure. The extraction of the second electron produces the bipolaron instead of two polarons, to which structural relaxations larger than those corresponding 


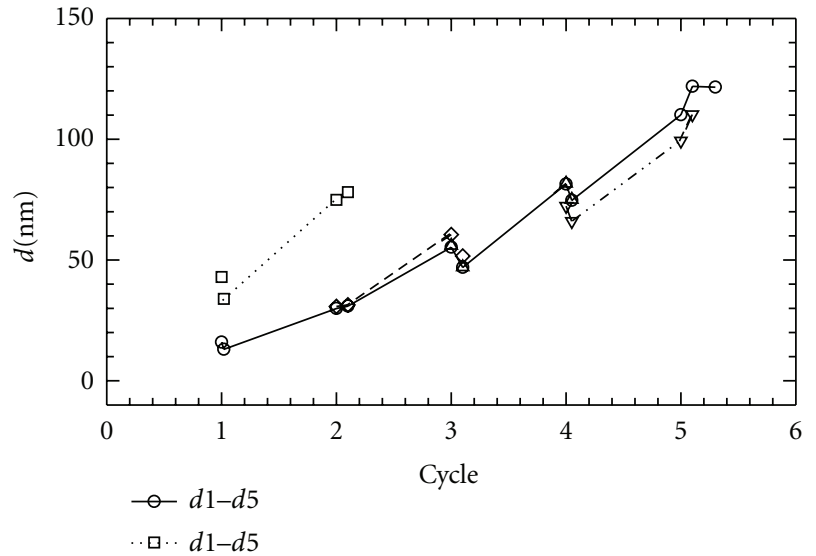

(a)

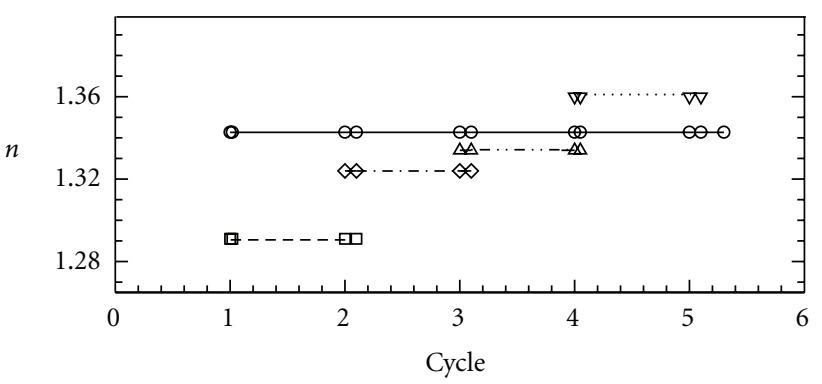

$\diamond-d 2-d 3$

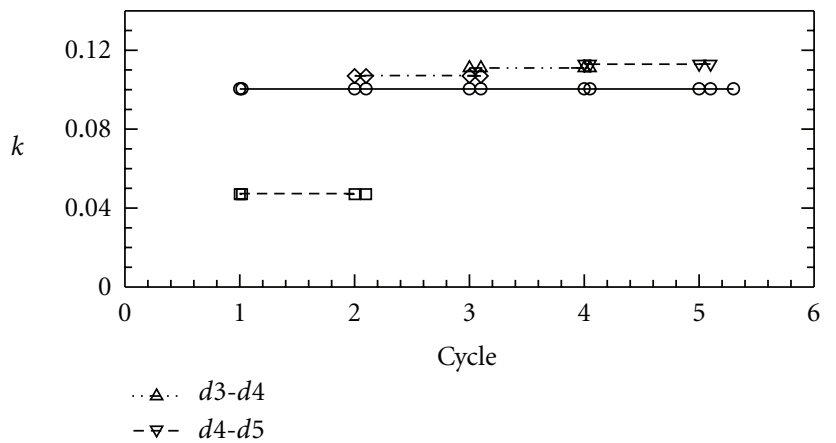

(b)

(c)

Figure 7: Calculated thickness, $d$, and optical indices, $n, k$, for the Ppy layers already described in Figure $3(\mathrm{a}), E a=1.2 \mathrm{~V}, \tau=20 \mathrm{~s}$. SDS solution, $\lambda=546 \mathrm{~nm}$. The different values $n$ and $k$ correspond to the resulting fitted values for different set of thicknesses.

to the polarons occur. Several $\pi-\pi^{*}$ transitions and polarons band are reported for different Ppy/doped layers [37, 38]. A band at $584 \mathrm{~nm}$ may be surmised as an antipolaron to a bipolaron band transition.

The experiment in Figure 5 shows a probable maximum polaron effect at the equilibrium potential $\mathbf{E}_{\mathbf{e q}}$ corresponding to $50 \%$ oxidation of the chains. On the other side, these kinds of experiments show that $\mathbf{E}_{\mathbf{e q}}$ which is associated with the voltametric peak potentials and the amenable maximal reduction state depends on the structure, compactness, and electronic conductivity of the network and the characteristic of the counterions than spreads through the membrane.

Moreover during Ppy reduction, the penetration of the cation into the membrane may flatten the smaller indentations [39]. Furthermore, overoxidation produces a decrease in conductance and probably in the concentration of the polaron after effect of the disruption of the conjugated doubled bond structure [40].

Figures 7 and 8 correspond to the plot of the fitted $n$, $k$, and $d$ values taking either the complete or smaller sets of successive thicknesses. Common values for $n$ and $k$ are assumed as a boundary condition. A linear increase of $d$ is observed starting from the second cycle together with a small increase in the values of $n$ and $k$. The initial thickness of the oligomers attached to the surface in the first and the second cycle can be estimated of about $40 \mathrm{~nm}$. After an initial deposit of $40 \mathrm{~nm}$, the second cycle produces the compactness of the first deposited layer with practically no change in thickness. In these calculations, $n$ and $k$ are considered as independent parameters. However they become related parameters using a more exhaustive analysis of Kramers-Kronig. In this case the optical data should be measured in a wide range of wavelengths. On the other side, the Maxwell Garnett and Bruggeman formalisms predict that both $n$ and $k$ must increase for a more compacted composite material, in the conditions of decreasing the volume fraction corresponding to the electrolyte [36]. In Figure 7, a small decrease in thickness during the successive optical measures taken at $0.1 \mathrm{~V}$ with intervals of $1 \mathrm{~min}$ that corresponds to the aging or the so-called first cycle or memory effect in the Ppy layer also can be noticed after each cycle.

In the case of the experiment using $E a=1.4 \mathrm{~V}$, Figure 8, the scheme corresponding to a film increasing in compactness at constant thickness prevails up to the third cycle with a thickness of about $100 \mathrm{~nm}$. After the third cycle, the layer starts to thicken with practically fixed $n$ and $k$ values.

Figure 9 shows the $\Delta / \Psi$ evolution during the first deposition cycles. In the graphics, theoretical curves corresponding to the film increasing in thickness each $8 \mathrm{~nm}$ with constant $n$ and $k$ values, namely, $n=1.343-i 0.100,1.291-i 0.047$, and $1.376-i 0.0723$, corresponding of the fitted values obtained taking the complete set of cycles are also plotted. Likewise, the theoretical $\Delta / \Psi$ corresponding to films of either 130,100 , 70 , or $40 \mathrm{~nm}$ whose optical indices decrease progressively 


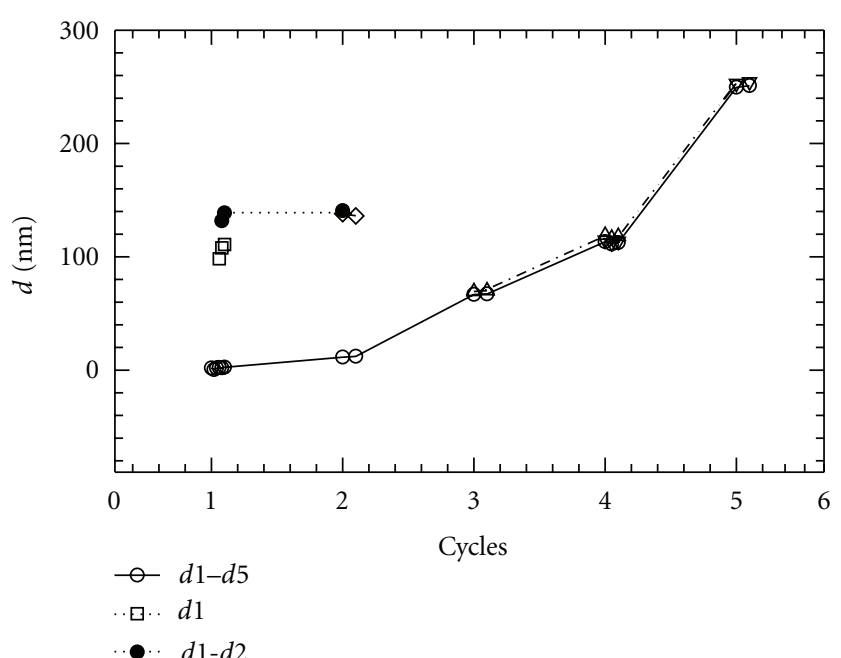

(a)

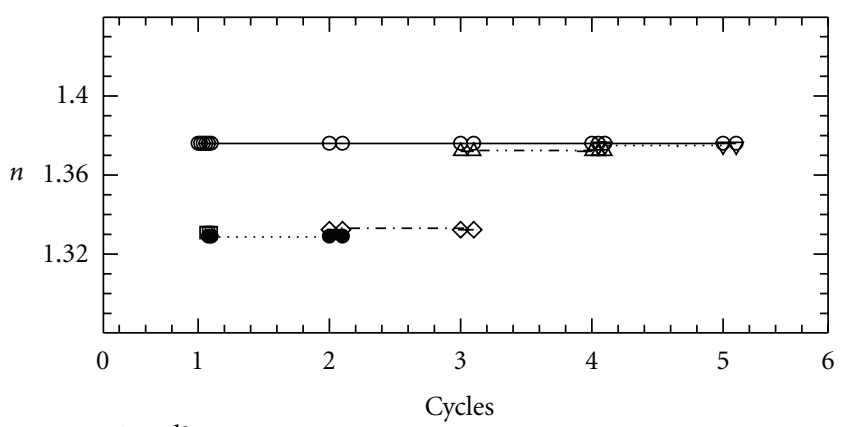

$\diamond-d 2$

$-\Delta \cdot \cdot d 3-d 4$

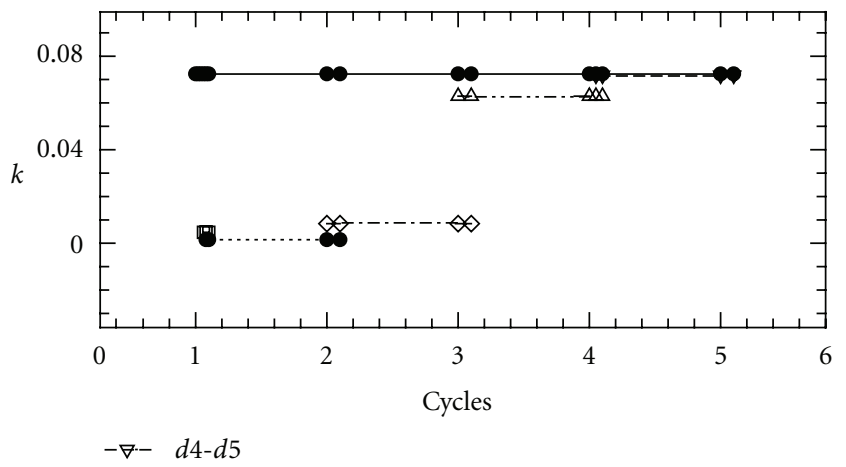

(b)

(c)

FIgure 8: Calculated thickness, $d$, and optical indices, $n, k$, for the Ppy layers already described in Figure 3(b). Ea = 1.4 V, $\tau=15 \mathrm{~s}$. SDS solution, $\lambda=546 \mathrm{~nm}$. The different values $n$ and $k$ correspond to the resulting fitted values for different set of thicknesses.

according to the Bruggeman relationship starting from the mentioned $n-i k$ values to the values of $n=1.332$ and $k=0$ corresponding to the electrolyte are plotted. Figure 9 shows similar calculations to that described in Figures 7 and 8. It states as for films of low thickness very similar evolution in $\Delta / \Psi$ results for both (I) $d$ increasing with constant $n$ and $k$ indices or (II) $n$ and $k$ increasing at constant $d$ values.

In the case of the films formed using 5 cycles at $1.4 \mathrm{~V}$ and $1.2 \mathrm{~V}$ and assuming average values for the oxidised and the reduced state, the calculated $d$ versus $Q$ rate is equal to $1 \mu \mathrm{m}$ for $7.3 \mathrm{mC} / \mathrm{cm}^{2}$ and $1 \mu \mathrm{m}$ for $11.6 \mathrm{mC} / \mathrm{cm}^{2}$ of cathodic charge, respectively. This charge is similar to the reported for other thin films and about twenty times lower than the anodic charge used in the deposition process $[8,28]$. The deposited layer at $1.4 \mathrm{~V}$ is obtained with a higher water contains. The currents of the peaks corresponding to the oxidation and the reduction of the deposited Ppy, Figure 1, indicate higher swelling and shrinking in the case of the film formed at $1.4 \mathrm{~V}$ than in the case of that formed at $1.2 \mathrm{~V}$.

Divers articles had reported the swelling and shrinking process in several systems.

The mechanism of swelling can be originated by (1) insertion and extraction of bulky ions, (2) conformation change of a structure due to the delocalisation of $\pi$-electrons and formation of polarons and bipolarons, (3) electrostatic repulsion between charges of the same sign [41]. Classical molecular dynamic simulation of Ppy/water interface holds that Ppy/Ppy interaction prevail over Ppy/water interactions in the reduced state, while the oxidised state induces more favourable Ppy/water interactions. The high hydrophobicity of the reduced Ppy expels the water from the bulk polymer. A density of 70 atoms $/ \mathrm{nm}^{3}$ was estimated for the reduced state [42].

Nevertheless, different mechanisms can prevail, and diverse effects have been reported

PPy/PPS network expands due to the insertion of anions in the oxidation and shrinks (extraction of anions) in the reduction [41]. Ppy/PTS swells on reduction and shrinks on oxidation. Charge compensation is probably accomplished by the cation transport rather than anion expulsion from the polymer matrix [43].

In $\mathrm{Ppy} / \mathrm{ClO}_{4}^{-}$is reported $30 \%$ decrease in thickness during oxidation. This seems strange with the expansion due to anion incorporation and electrostriction is considered as the controlling mechanism. Ppy/DBS expands about $61 \%$ by reduction $[23,25]$.

In the case of Ppy/SDS film, the deposition at $1.2 \mathrm{~V}$ forms compact layers where SDS stabilise the Ppy in the 


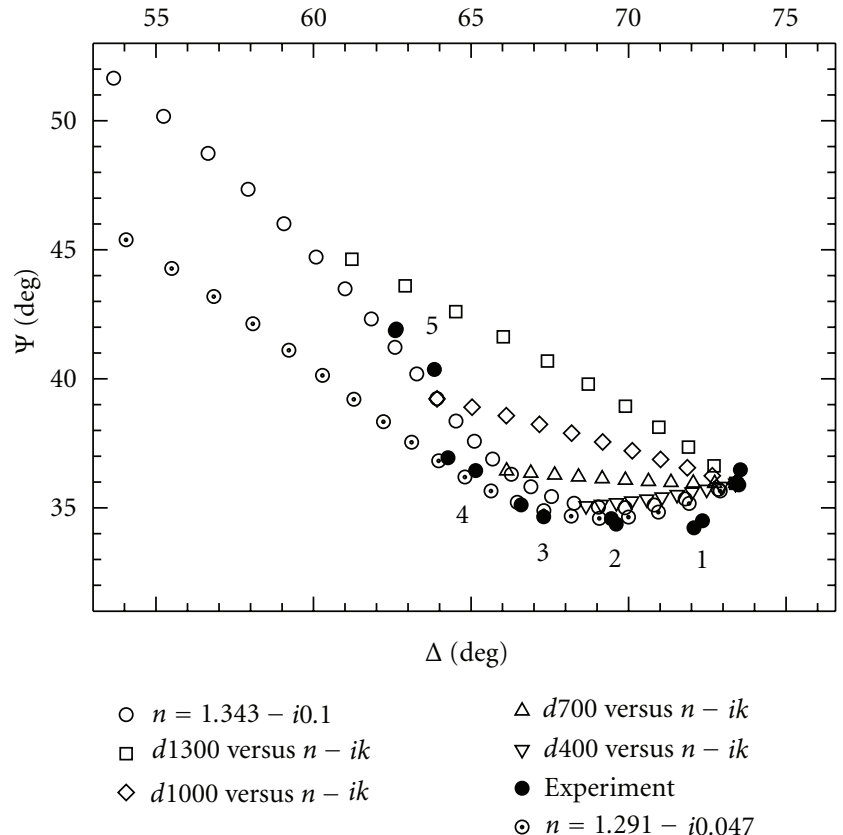

(a)

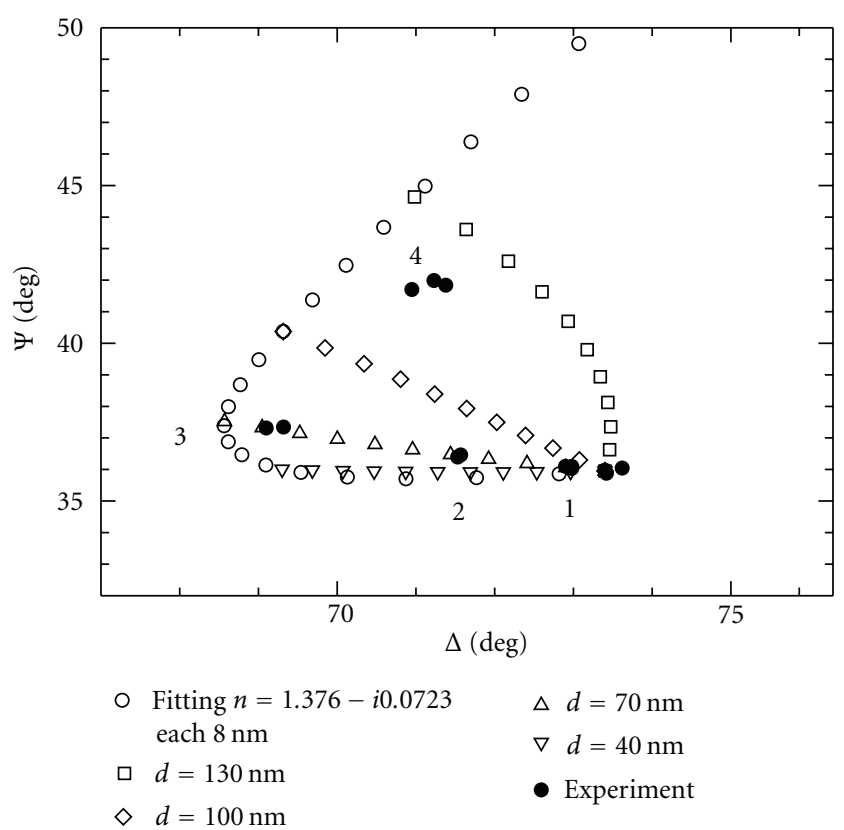

(b)

Figure 9: Enlarged plots of Ppy layers showing $\Delta / \Psi$ values corresponding to the first cycles shown in Figure 3 . $(\bullet)$ experimental points, (a) $E a=1.2 \mathrm{~V}$, (b) $E a=1.4 \mathrm{~V}$. The figures correspond to number of cycles. Open points corresponds to different growing models: $(\odot$, $\bigcirc)$ increasing $d$ holding $n$ and $k$ fixed; $(\square, \diamond, \Delta, \nabla)$ decreasing both $n$ and $k$ for different $d$ fixed values, namely $d=130,100,70$ and $40 \mathrm{~nm}$, respectively.

high oxidised state. In $\mathrm{KCl}$ solution, Ppy shrinks showing an increasing polaronic effect for middle oxidation charge, water expulsion, and cation insertion. The high sensibility and reproducibility of the process may indicate the presence of a composite gel/electrolyte [30, 44, 45].

The Ppy $/ \mathrm{PO}_{4}^{-3}$ electrodeposited at $E a=1.2 \mathrm{~V}$ and $1.4 \mathrm{~V}$ in phosphate buffer show higher optical indices, $n=1.50-$ i0.07, and an increase of $d$ for the successive cycles starting from the second one, holding $n$ and $k$ quasi constants. On the other side, at a relatively very low potential, $E a=0.9 \mathrm{~V}$, a thick Ppy layer grows. Its thickness is about $80 \mathrm{~nm}$ and an initial very low optical density similar to that of the electrolyte increases with the number of cycles [15]. In the case of Ppy/SDS, the initial cycles show a very low optical density at $E a=1.2 \mathrm{~V}$, and the mean thickness of the initial dispersed attached oligomer increases for increasing $E a=1.4 \mathrm{~V}$. In this electrolyte, the monomer is extensively dissolved into the SDS micelles, and the electro polymerisation leads towards an initially more dispersed film than in $\mathrm{PO}_{4}^{-3}$ solution. The surfactant may also modify the growing process, induce the formation of ion pairing, and promote the Py polymerisation $[46,47]$.

\section{Conclusions}

The Ppy/SDS layer grown by successive potential pulses shows an initially low optical index $n-i k$, and thickness $d_{i}$ of about $100 \mathrm{~nm}$. The density and optical indices $n-i k$ of the layer increase after the successive pulses up to a maximum value $n-i k$, holding constant $d$, after which the film grows in thickness holding constant density and $n-i k$ indices.

The fitted $d$ depends on the anodic limit $E a$, increasing with $E a$, and $d_{i}=40 \mathrm{~nm}$ and $d_{i}=100 \mathrm{~nm}$ result from anodic polarisation at $E a=1.2 \mathrm{~V}$ and $E a=1.4 \mathrm{~V}$, respectively.

The film grown at $E a=1.2 \mathrm{~V}$ is more compact, shows low pseudocapacity, and stays in a high oxidation state, even under cathodic polarisation. After dipping in $\mathrm{KCl}$ solution, significant increases in pseudocapacity and electrochromism come out.

The Ppy/SDS layer grown at $E a=1.4 \mathrm{~V}$ shows swelling under cathodic polarisation in SDS and $\mathrm{KCl}$ solutions. The Ppy/SDS layer grown at $E a=1.2 \mathrm{~V}$ is very inert under switching in SDS solution. However, it shows significant shrinking under cathodic polarisation in $\mathrm{KCl}$ solution.

\section{Acknowledgments}

Authors are grateful to the "Comisión de Investigaciones Científicas de la Prov. de Bs. As." (CIC) and the Universidad Nacional de San Luis (UNSL) for their grants to support this work. J. O. Z is member of the Research Career of CIC and M. G. S. of the Research Career of CONICET.

\section{References}

[1] S. Barnoss, H. Shanak, C. C. Bof Bufon, and T. Heinzel, "Piezoresistance in chemically synthesized polypyrrole thin films," Sensors and Actuators A, vol. 154, no. 1, pp. 79-84, 2009. 
[2] K. S. Teh, Y. Takahashi, Z. Yao, and Y. W. Lu, "Influence of redox-induced restructuring of polypyrrole on its surface morphology and wettability," Sensors and Actuators A, vol. 155, no. 1, pp. 113-119, 2009.

[3] M. M. Chehimi, M. L. Abel, Z. Sahraoui, K. Fraoua, S. F. Lascelles, and S. P. Armes, "Time-dependent variation of the surface energy of conducting polypyrrole," International Journal of Adhesion and Adhesives, vol. 17, no. 1, pp. 1-8, 1997.

[4] D. Ge, X. Tian, R. Qi et al., "A polypyrrole-based microchip for controlled drug release," Electrochimica Acta, vol. 55, no. 1, pp. 271-275, 2009.

[5] X. Luo and X. T. Cui, "Sponge-like nanostructured conducting polymers for electrically controlled drug release," Electrochemistry Communications, vol. 11, no. 10, pp. 1956-1959, 2009.

[6] J. K. Lim, J. W. Ciszek, F. Huo, J. W. Jang, S. Hwang, and C. A. Mirkin, "Actuation of self-assembled two-component rodlike nanostructures," Nano Letters, vol. 8, no. 12, pp. 4441-4445, 2008.

[7] G. S. Gohil, V. V. Binsu, and V. K. Shahi, "Preparation and characterization of mono-valent ion selective polypyrrole composite ion-exchange membranes," Journal of Membrane Science, vol. 280, no. 1-2, pp. 210-218, 2006.

[8] D. O. Flamini and S. B. Saidman, "Electrodeposition of polypyrrole onto NiTi and the corrosion behaviour of the coated alloy," Corrosion Science, vol. 52, no. 1, pp. 229-234, 2010.

[9] G. Paliwoda-Porebska, M. Rohwerder, M. Stratmann, U. Rammelt, L. M. Duc, and W. Plieth, "Release mechanism of electrodeposited polypyrrole doped with corrosion inhibitor anions," Journal of Solid State Electrochemistry, vol. 10, no. 9, pp. 730-736, 2006.

[10] M. Rohwerder and A. Michalik, "Conducting polymers for corrosion protection: what makes the difference between failure and success?" Electrochimica Acta, vol. 53, no. 3, pp. 13011314, 2007.

[11] S. de Marcos and O. S. Wolfbeis, "Optical sensing of $\mathrm{pH}$ based on polypyrrole films," Analytica Chimica Acta, vol. 334, no. 12, pp. 149-153, 1996.

[12] A. Riul, A. M. G. Soto, S. V. Mello, S. Bone, D. M. Taylor, and L. H. C. Mattoso, "An electronic tongue using polypyrrole and polyaniline," Synthetic Metals, vol. 132, no. 2, pp. 109-116, 2003.

[13] Y. C. Liu and B. J. Hwang, "Mechanism of conductivity decay of polypyrrole exposed to water and enhancement of conductivity stability of copper(I)-modified polypyrrole," Journal of Electroanalytical Chemistry, vol. 501, no. 1-2, pp. 100-106, 2001.

[14] A. Gratton, B. J. Hoffer, and G. A. Gerhardt, "In vivo electrochemical studies of monamine release in the mendial prefrontal cortes of the rat," Neuroscience, vol. 29, no. 1, pp. 57-64, 1989.

[15] J. O. Zerbino, L. J. H. Pesetti, and M. G. Sustersic, "Electrochemical and ellipsometric study of polypyrrol films in solutions containing ascorbic acid," Journal of Molecular Liquids, vol. 131-132, pp. 185-189, 2007.

[16] J. Bobacka, A. Ivaska, and A. Lewenstam, "Potentiometric ion sensors," Chemical Reviews, vol. 108, no. 2, pp. 329-351, 2008.

[17] Z. Gao, Z. Minxian, and C. Beshen, "The influence of overoxidation treatment on the permeability of polypyrrole films," Journal of Electroanalytical Chemistry, vol. 373, no. 12, pp. 141-148, 1994.

[18] Z. Gao and A. Ivaska, "Electrochemical behaviour of dopamine and ascorbic acid at overoxidized polypyrrole(do- decyl sulphate) film-coated electrodes," Analytica Chimica Acta, vol. 284, no. 2, pp. 393-404, 1993.

[19] F. Beck, P. Braun, and M. Oberst, "Organic electrochemistry in the solid state-overoxidation of polypyrrole," Berichte der Bunsengesellschaft für Physikalische Chemie, vol. 91, no. 9, pp. 967-974, 1987.

[20] W. J. Plieth, J. Zerbino, C. Lahmann, and G. Kossmehl, "Examination of electrically conducting films of poly $(2,5-$ thiophenediyl) by cyclic voltanunetry and ellipsometry. Part II," Journal of Electroanalytical Chemistry, vol. 274, no. 1-2, pp. 213-224, 1989.

[21] J. O. Zerbino, W. J. Plieth, and G. Kossmehl, "Optical properties of electrically conducting films formed by anodic oxidation of 1,2-di(2-thienyl)ethylene," Journal of Applied Electrochemistry, vol. 21, no. 10, pp. 935-940, 1991.

[22] E. Kriván, C. Visy, and J. Kankare, "Deprotonation and dehydration of pristine PPy/DS films during open-circuit relaxation: an ignored factor in determining the properties of conducting polymers," Journal of Physical Chemistry B, vol. 107, no. 6, pp. 1302-1308, 2003.

[23] E. Smela and N. Gadegaard, "Volume change in polypyrrole studied by atomic force microscopy," Journal of Physical Chemistry B, vol. 105, no. 39, pp. 9395-9405, 2001.

[24] P. A. Christensen and A. Hamnett, "In situ spectroscopic investigations of the growth, electrochemical cycling and overoxidation of polypyrrole in aqueous solution," Electrochimica Acta, vol. 36, no. 8, pp. 1263-1286, 1991.

[25] A. Hamnett, P. A. Christensen, and S. J. Higgins, "Analysis of electrogenerated films by ellipsometry and infrared spectrometry," The Analyst, vol. 119, no. 5, pp. 735-747, 1994.

[26] S. Li, Y. Qiu, and X. Guo, "Influence of doping anions on the ion exchange behavior of polypyrrole," Journal of Applied Polymer Science, vol. 114, no. 4, pp. 2307-2314, 2009.

[27] C. Zhong, K. Doblhofer, and G. Weinberg, "The effect of incorporated negative fixed charges on the membrane properties of polypyrrole films," Faraday Discussions of the Chemical Society, vol. 88, pp. 307-316, 1989.

[28] J. O. Zerbino, M. I. Florit, and A. Maltz, "Voltammetric and ellipsometric study of electrically conducting films of poly(otoluidine) in different acid media," Electrochimica Acta, vol. 44, no. 12, pp. 1973-1979, 1999.

[29] J. O. Zerbino and M. G. Sustersic, "Ellipsometric and electrochemical study of dopamine adsorbed on gold electrodes," Langmuir, vol. 16, no. 19, pp. 7477-7481, 2000.

[30] J. Heinze, B. A. Frontana-Uribe, and S. Ludwigs, "Electrochemistry of conducting polymers-persistent models and new concepts," Chemical Reviews, vol. 110, no. 8, pp. 4724-4771, 2010.

[31] P. R. Teasdale and G. G. Wallace, "In situ characterization of conducting polymers by measuring dynamic contact angles with Wilhelmy's plate technique," Reactive Polymers, vol. 24, no. 3, pp. 157-164, 1995.

[32] H. Yamato, M. Ohwa, and W. Wernet, "Stability of polypyrrole and poly(3,4-ethylenedioxythiophene) for biosensor application," Journal of Electroanalytical Chemistry, vol. 397, no. 1-2, pp. 163-170, 1995.

[33] I. L. Lehr, O. V. Quinzani, and S. B. Saidman, "Comparative study of polypyrrole films electrosynthesized in alkaline and acid solutions," Materials Chemistry and Physics, vol. 117, no. 1, pp. 250-256, 2009.

[34] C. Zhong and K. Doblhofer, "Polypyrrole-based electrode coatings switchable electrochemically between the anion- and cation-exchanger states," Electrochimica Acta, vol. 35, no. 1112, pp. 1971-1976, 1990. 
[35] J. O. Zerbino, C. Falivene, A. Maltz, and M. G. Sustersic, "Polypyrrole films electropolymerised in sodium doedecylsulphate solution," Avances en Ciencias e Ingenieria, vol. 1, no. 4, pp. 23-32, 2010.

[36] M. E. Vela, J. O. Zerbino, and A. J. Arvia, "Ellipsometric study of hydrous gold oxide layers and gold surfaces resulting from their electroreduction," Thin Solid Films, vol. 233, no. 1-2, pp. 82-85, 1993.

[37] S. Little, S. F. Ralph, C. O. Too, and G. G. Wallace, "Solvent dependence of electrochromic behaviour of polypyrrole: rediscovering the effect of molecular oxygen," Synthetic Metals, vol. 159, no. 19-20, pp. 1950-1955, 2009.

[38] S. Chakrabarti, D. Banerjee, and R. Bhattacharyya, "Enhancement of room temperature electrical conductivity of polypyrrole by chemical modification," Journal of Physical Chemistry $B$, vol. 106, no. 12, pp. 3061-3064, 2002.

[39] Y. W. Lu, Y. Takahashi, and K. S. Teh, "Wettability switching technique of a biocompatible polymer for protein adhesion control," in Proceedings of the 22nd Annual IEEE International Conference on Micro Electro Mechanical Systems (MEMS '09), Sorrento, Italy, January 2009.

[40] T. F. Otero, P. Herrasti, P. Ocón, and C. R. Alves, "Electrogeneration of polypyrrole-carboxymethylcellulose composites: electrochemical, microgravimetric and morphological studies," Electrochimica Acta, vol. 43, no. 9, pp. 1089-1100, 1998.

[41] M. Fuchiwaki, W. Takashima, S. S. Pandey, and K. Kaneto, "Proposal of novel actuators using conducting polymer laminates," Synthetic Metals, vol. 135-136, pp. 135-136, 2003.

[42] J. J. López Cascales, A. J. Fernández, and T. F. Otero, "Characterization of the reduced and oxidized polypyrrole/water interface: a molecular dynamics simulation study," Journal of Physical Chemistry B, vol. 107, no. 35, pp. 9339-9343, 2003.

[43] M. F. Suárez and R. G. Compton, "In situ atomic force microscopy study of polypyrrole synthesis and the volume changes induced by oxidation and reduction of the polymer," Journal of Electroanalytical Chemistry, vol. 462, no. 2, pp. 211221, 1999.

[44] E. Ruckenstein and J.-H. Chen, "Polypyrrole conductive composites prepared by coprecipitation," Polymer, vol. 32, no. 7, pp. 1230-1235, 1991.

[45] K. Aoki and M. Kawase, "Introduction of a percolation threshold potential at polyaniline-coated electrodes," Journal of Electroanalytical Chemistry, vol. 377, no. 1-2, pp. 125-129, 1994.

[46] G. Zotti, G. Schiavon, S. Zecchin, F. Sannicolo, and E. Brenna, "Anion-assisted anodic coupling of 2,2'-bipyrrole. Role of tosylate anion in the electrochemical synthesis of polypyrrole," Chemistry of Materials, vol. 7, no. 8, pp. 1464-1468, 1995.

[47] L. M. Abrantes and J. P. Correia, "On the initiation and growth of polymer films onto electrode surfaces," Electrochimica Acta, vol. 44, no. 12, pp. 1901-1910, 1999. 


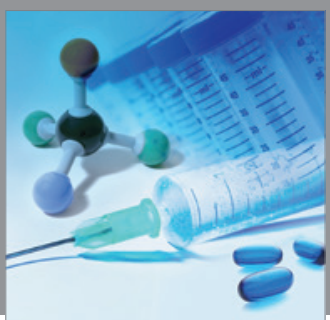

International Journal of

Medicinal Chemistry

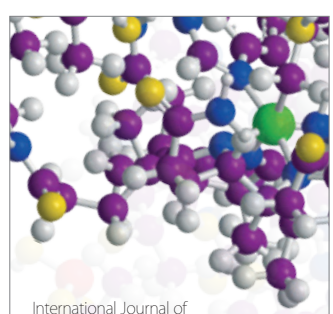

Carbohydrate Chemistry

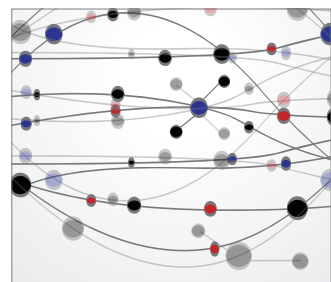

The Scientific World Journal
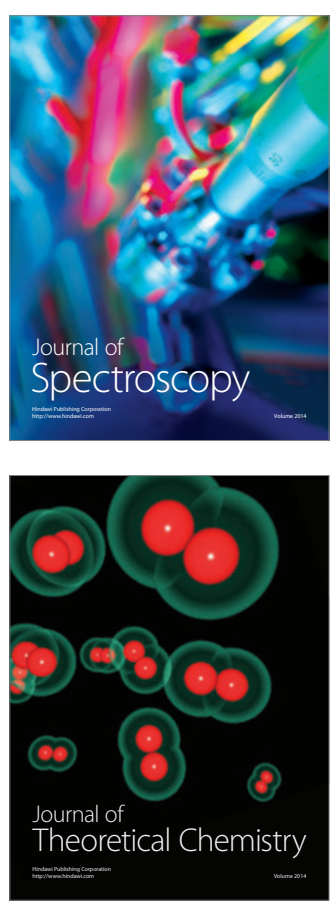
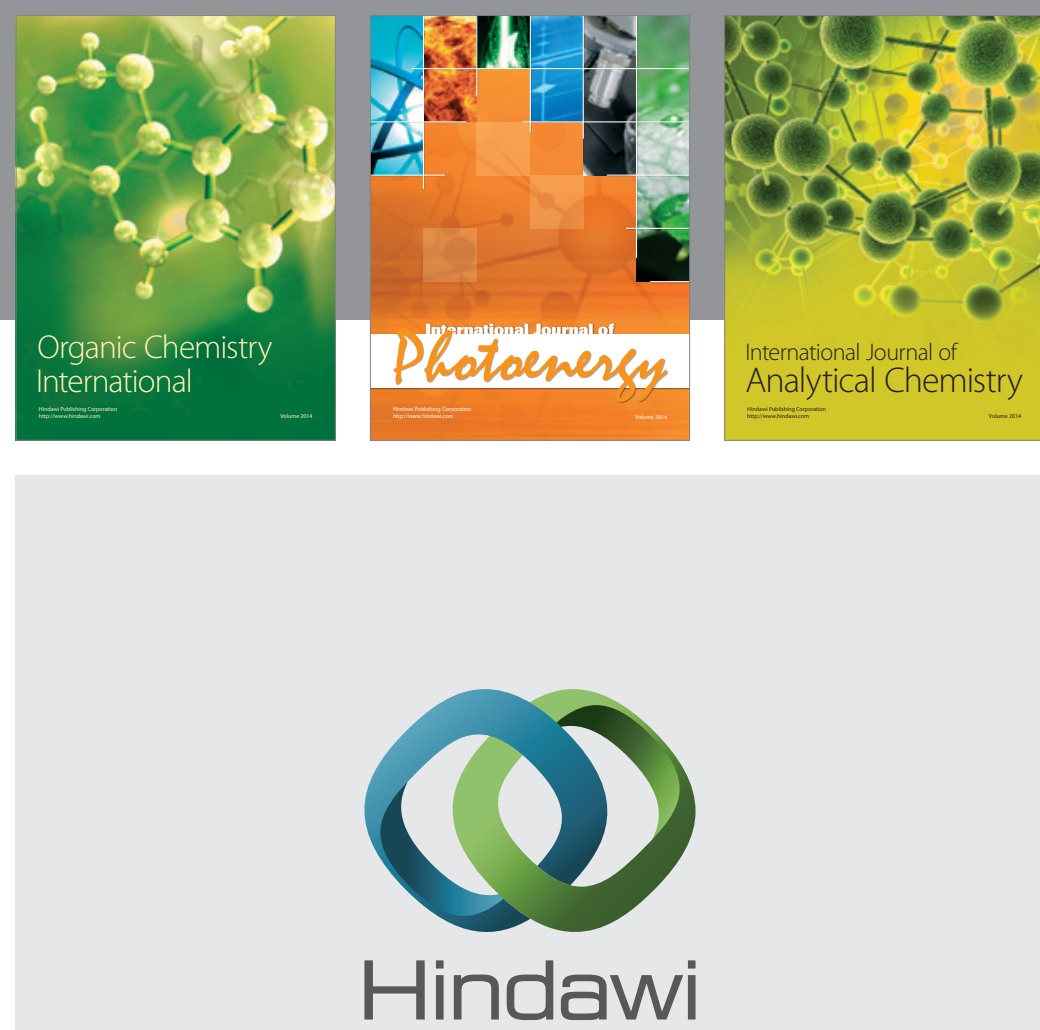

Submit your manuscripts at

http://www.hindawi.com
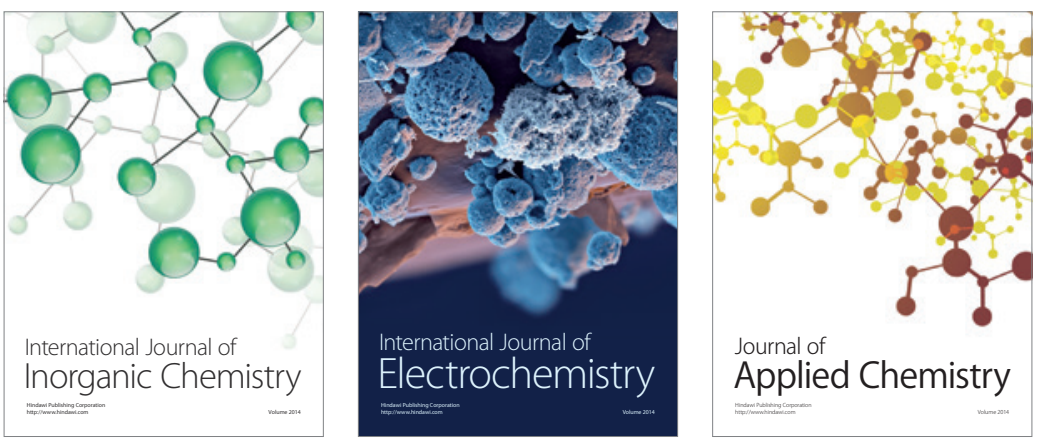

Journal of

Applied Chemistry
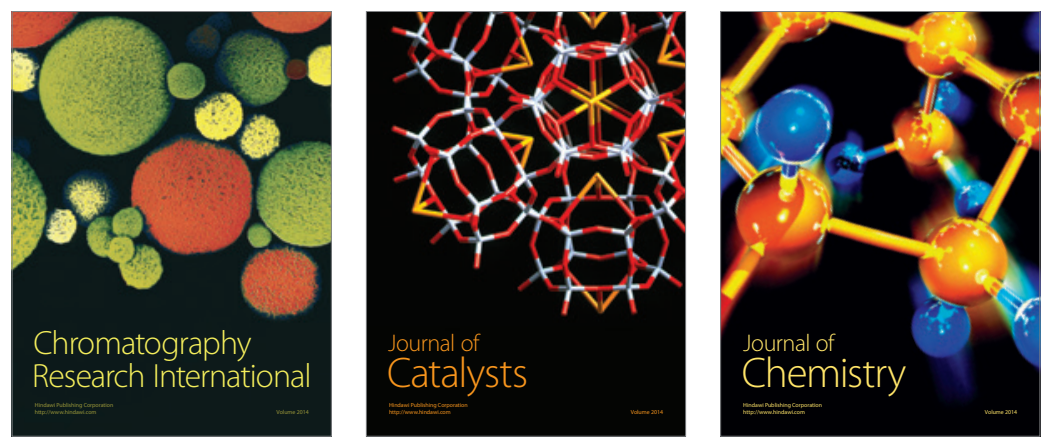
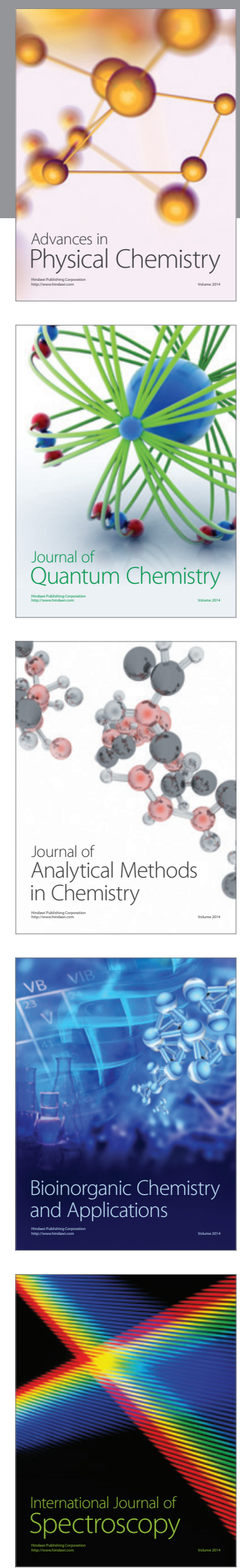